\title{
PENGARUH PERBEDAAN KONSENTRASI TAPIOKA TERHADAP SIFAT FISIKOKIMIA DAN ORGANOLEPTIK KWETIAU KERING BERAS HITAM DENGAN PENAMBAHAN SODIUMTRIPOL YPHOSPHATE
}

\author{
(Effect of Difference in Concentration of Tapioca Starch to the \\ Physicochemical and Organoleptic Properties of Dry Black Rice Kwetiau \\ with Addition of Sodium Tripolyphosphate)
}

\author{
Brenda Christie $^{a^{*}}$, Sutarjo Surjoseputro ${ }^{a}$, Erni Setijawaty $^{a}$
}

aFakultas Teknologi Pertanian - Universitas Katolik Widya Mandala Surabaya, Indonesia

${ }^{*}$ Penulis korespondensi

Email:Christie.brenda@yahoo,com

\begin{abstract}
Kwetiau is a traditional food that is popular in Asia, especially East Asia and Southeast Asia. In general, kwetiau are made from white rice and has a chewy, smooth and soft texture. The variety of rice noodles is less diverse and with the aim of diversifying kwetiau, in this study, black rice is used as the main raw material. However, dry black rice kwetiau are easily broken and less elastic. One way to overcome this, is to add tapioca starch to the puree mixture. Addition of tapioca starch can improve the characteristics of kwetiau because of amylose and amylopectin which can form the structure of matrix so it can produce a chewy and elastic dry black rice kwetiau. The research design used a randomized block design (RBD) with one factor, namely tapioca starch concentration consisting of seven levels, namely $4 \%, 6 \%, 8 \%$, $10 \%, 12 \%, \& 14 \%$ and $16 \%$ of the weight of black rice puree used. This experiment was repeated four times. The parameters are moisture content, water activity, rehydration power, extension, elasticity, color, and organoleptic (taste, color and elasticity). Different concentration of tapioca starch decreased water content (8.17\%-10.14\%), decreased water activity (0.455-0.666), increased rehydration ratio (68.19\%$113.89 \%)$, increased extensibility (29.63 mm-31.77 mm), and increased elasticity (0.71-1.06). Lightness range (22.13-24.11), chroma range (1.15-1.47), hue range (284.170 $\left.-336.63^{\circ}\right)$ for dried color, also lightness range (34.24-38.76), chroma (2.23-3.41), hue (345.27-356.09') for color after rehydration and cooking.
\end{abstract}

Keywords: kwetiau, black rice, tapioca starch

\begin{abstract}
ABSTRAK
Kwetiau merupakan makanan tradisional yang populer di Asia terutama Asia Timur dan Asia Tenggara. Pada umumnya, kwetiau berbahan dasar beras putih dan memiliki tekstur kenyal, halus serta lembut. Variasi kwetiau yang kurang beragam dan dengan tujuan penganekaragaman jenis kwetiau maka pada penelitian ini digunakan beras hitam sebagai bahan baku utama. Namun, penggunaan beras hitam sebagai bahan baku kwetiau kering akan menghasilkan karakteristik kwetiau yang mudah patah dan kurang elastis. Salah satu cara untuk mengatasi hal tersebut adalah menambahkan pati tapioka ke dalam adonan kwetiau. Penambahan pati tapioka dapat memperbaiki karakteristik kwetiau beras hitam yang dihasilkan karena adanya amilosa dan amilopektin yang dapat membentuk struktur matriks kwetiau sehingga menhasilkan kwetiau kering beras hitam yang kenyal dan elastis. Rancangan penelitian yang digunakan adalah Rancangan Acak Kelompok (RAK) dengan satu faktor yaitu konsentrasi pati tapioka yang terdiri dari tujuh level, yaitu $4 \%, 6 \%, 8 \%, 10 \%, 12 \&, 14 \%$ dan $16 \%$ dari berat bubur beras hitam
\end{abstract}


yang digunakan. Percobaan ini diulang sebanyak empat kali. Parameter yang diuji yaitu kadar air, aktivitas air, daya rehidrasi, ekstensibilitas, elastisitas, warna, dan organoleptik (rasa, warna dan kekenyalan). Perbedaan tapioka yang semakin banyak menghasilkan penurunan kadar air $(8,17 \%-$ $10,14 \%)$, penurunan aw $(0,455-0,666)$, penngkatan daya rehidrasi $(68,19 \%-113,89 \%)$, peningkatan ekstensibilitas $(29,63 \mathrm{~mm}-31,77 \mathrm{~mm})$, dan peningkatan elastisitas $(0,71-1,06)$. Rentang nilai lightness $(22,13-24,11)$, chroma $(1,15-1,47)$, dan hue $\left(284,17^{\circ}-336,63^{\circ}\right)$ untuk warna kering. Rentang nilai lightness $(34,24-38,76)$, chroma $(2,23-3,41)$ dan hue $\left(345,27^{\circ}-356,09^{\circ}\right)$ untuk warna kwetiau kering setelah direhidrasi dan dimasak. Perlakuan terbaik yang dipilih berdasarkan uji organoleptik dengan metode spiderweb adalah konsentrasi tapioka $14 \%$.

Kata kunci: kwetiau, beras hitam, tapioka

\section{PENDAHULUAN}

Kwetiau merupakan makanan tradisional yang populer di Asia terutama Asia Timur dan Asia Tenggara (Fadiati et al., 2014). Pada umumnya, kwetiau kering yang berada di pasar berbahan dasar beras putih. Variasi kwetiau kering yang kurang beragam dan dengan tujuan penganekaragaman jenis kwetiau kering maka pada penelitian ini digunakan beras hitam sebagai bahan baku utama yang dapat memberikan nilai tambah bagi konsumen.

Beras hitam merupakan varietas lokal yang mulai populer dan memiliki nilai tambah bagi konsumen (Mangiri et al., 2016). Beras hitam memiliki kandungan serat sebanyak 7,6 (g/100g) (Hernawan dan Vita, 2016). Beras hitam mengandung senyawa antioksidan berupa senyawa antosianin yang tinggi yaitu $80 \%$ (Caro et al., 2013). Selain itu beras hitam memiliki rasa "nutty" dan tekstur yang halus (Ujawall, 2016).

Kwetiau yang berbahan dasar beras hitam memiliki sifat kurang elastis setelah direhidrasi. Sifat kurang elastis tersebut dikarenakan kandungan amilosa dalam beras hitam 39,41\% dan amilopektin $60,59 \%$ (Hernawan dan Vita, 2016). Kandungan tersebut akan mempengaruhi penyerapan jumlah air dalam bahan yang akan menentukan karakteristik kwetiau kering yang dihasilkan. Semakin tinggi jumlah air yang diserap maka kwetiau kering yang dihasilkan tidak mudah patah dan elastis.
Salah satu cara memperbaiki karaketeristik kwetiau kering beras hitam tersebut adalah menambahkan pati kedalam adonan kwetiau. Pati yang biasanya digunakan pada kwetiau kering adalah pati tapioka (Fu, 2008). Menurut Anggraini (2002), pati tapioka memiliki kandungan amilopektin yang tinggi (83\%). Peran pati tapioka tersebut akan terjadi pada proses gelatinisasi saat pemasakan. Gelatinisasi merupakan proses masuknya air ke dalam pati yang menyebabkan terjadinya pembengkaan granula. Pembengkaan granula tersebut akan menyebabkan amilosa dan amilopektin berdifusi keluar dari granula dan akan membentuk matriks yang seragam sehingga kekuatan ikatan antar granula meningkat (Juniawati, 2003).

Pada penelitian ini penambahan pati tapioka dalam kwetiau kering beras hitam dapat memberikan sifat kenyal dan elastis namun dapat menurunkan daya rehidrasi kwetiau kering beras hitam sehingga perlu ditambahkan STPP sebesar $0,4 \%$ yang bertujuan untuk meningkatkan daya rehidrasi tersebut. Berdasarkan penelitian pendahuluan, penambahan STPP $0,4 \%$ memberikan daya rehidrasi yang baik. Batas penggunaan STPP adalah 0,5\%, jika melebihi akan mempengaruhi kenampakan produk dan terasa pahit (Harahap, 2007).

Penambahan pati tapioka dapat mempengaruhi sifat fisikokimia dan organoleptik kwetiau beras hitam yang dihasilkan. Pada penelitian ini diharapkan penambahan pati tapioka dapat memperbaiki karakteristik kwetiau beras 
hitam yang dihasilkan. Pati tapioka yang ditambahkan sebesar 4\%, 6\%, 8\%, 10\%, $12 \%, 14 \%$ dan $16 \%$ dari berat adonan kwetiau. Penggunaan pati tapioka dibawah $4 \%$ akan menghasilkan kwetiau yang kurang kenyal, sedangkan batas maksimum pati yang ditambahkan sebesar 16\% dikarenakan di atas jumlah tersebut karakteristik kwetiau beras hitam yang dihasilkan menjadi lebih liat sehingga tidak memenuhi karakteristik kwetiau pada umumnya. Oleh karena itu, pada penelitian ini dilakukan penambahan berbagai konsentrasi pati tapioka yang dapat memberikan pengaruh terhadap karakteristik fisikokimia dan organoleptik kwetiau kering beras hitam.

\section{Bahan}

\section{BAHAN DAN METODE}

Bahan-bahan yang digunakan dalam penelitian ini adalah beras hitam varietas Jawa yang diperoleh dari CV. Shinta Rama, Jawa Tengah spesifikasi dapat dilihat pada Lampiran A.1., pati tapioka dengan merek "Cap Gajah Laut" diperoleh dari PT. ILUFAT, SodiumTripolyphosphate (STPP) yang diperoleh dari PT. Petrocentral, Air Minum Dalam Kemasan (AMDK) dan minyak goreng "Filma" yang diperoleh dari swalayan di Surabaya.

\section{Alat untuk proses}

Alat-alat yang digunakan pada pembuatan kwetiau kering beras hitam adalah kompor gas (Rinnai), pengukus, timbangan digital kasar (Ohaus SPJ6001), timbangan analitis (Ohaus PA 214), water jug, gelas ukur $10 \mathrm{~mL}$, blender (Panasonic), cabinet dryer, loyang stainless ukuran $(20 \times 20 \times 4) \mathrm{cm}$, dandang ukuran $(40 \times 40 \times 18)$, cup plastik, nampan, baskom, piring, telenan, pisau, stiker label, kuas, kain satin putih dan kain, plastic PP, solet, sendok, tray cabinet, thermometer infrared.

\section{Alat untuk analisa}

Alat-alat yang digunakan untuk analisa adalah kalkulator, timbangan analitis
(Ohaus PA 214), oven (Binder), botol timbang RRT, eksikator RRT, sarung tangan, sendok, plastik, nampan, cup plastik, pengaduk, gelas beker $250 \mathrm{~mL}$ (pyrex), gelas ukur $100 \mathrm{~mL}$ (Pyrex), aw meter (HygroPalm), texture analyzer (Lloyd tipe TA-XT plus), color reader (Minolta CR300), label, dan kuesioner uji organoleptik.

\section{Metode penelitian}

Rancangan percobaan yang digunakan adalah Rancangan Acak Kelompok (RAK) yang terdiri dari 1 faktor yaitu konsentrasi tapioka dengan taraf 7 (tujuh) perlakuan dan pengulangan sebanyak 4 (empat) kali. Formulasi pada proses pembuatan kwetiau kering beras hitam dengan perbedaan konsentrasi tapioka dapat dilihat pada Tabel 1.

Bahan yang digunakan dalam pembuatan kwetiau kering beras hitam adalah beras hitam yang telah direndam pada suhu ruang selama 8 jam dan dihancurkan menjadi bubur beras. Adonan bubur beras hitam dicampur dengan tapioka, air dan STPP serta diaduk sampai homogen. Kemudian dilakukan proses pencetakan dalam loyang dan dilakukan pengukusan $\left(100^{\circ} \mathrm{C}\right.$; 5 menit). Setelah itu, dilakukan proses pendinginan pada suhu kamar dan dilakukan proses pemotongan $\pm 1 \mathrm{~cm}$. Proses terakhir adalah pengeringan dengan cabinet dryer $\left(60^{\circ} \mathrm{C} ; 2\right.$ jam $)$.

\section{HASIL DAN PEMBAHASAN}

Pengujian fisikokimia kwetiau kering beras hitam meliputi kadar air, aktivitas air, daya rehidrasi, ekstensibilitas, elastisitas, dan warna serta pengujian organoleptik (rasa, warna, dan kekenyalan) dapat dilihat pada Tabel 2.

\section{Organoleptik}

Pengujian rasa dan kekenyalan kwetiau dilakukan dengan cara meminta panelis untuk menilai kesukaan terhadap aftertaste beras hitam dan kemudahan untuk dikunyah pada kwetiau kering beras hitam yang telah direhidrasi dan dimasak. 
Tabel 1. Formulasi Pembuatan Kwetiau Kering Beras Hitam

\begin{tabular}{lccccccc}
\hline \multirow{1}{*}{ Bahan } & \multicolumn{7}{c}{ Perlakuan } \\
& T1 & T2 & T3 & T4 & T5 & T6 & T7 \\
& $4 \%$ & $6 \%$ & $8 \%$ & $10 \%$ & $12 \%$ & $14 \%$ & $16 \%$ \\
\hline Bubur beras hitam $(\mathrm{g})$ & 672 & 658 & 644 & 630 & 616 & 602 & 588 \\
Pati tapioka $(\mathrm{g})$ & 28 & 42 & 56 & 70 & 84 & 98 & 112 \\
STPP $(\mathrm{g})$ & 28 & 28 & 28 & 28 & 28 & 28 & 28 \\
Air $(\mathrm{g})$ & 20 & 20 & 20 & 20 & 20 & 20 & 20 \\
Total $(\mathrm{g})$ & 748 & 748 & 748 & 748 & 748 & 748 & 748 \\
\hline
\end{tabular}

Tabel 2. Hasil Pengujian Fisikokimia Kwetiau Kering Beras Hitam

\begin{tabular}{|c|c|c|c|c|c|c|c|}
\hline \multirow{2}{*}{ Parameter } & \multicolumn{7}{|c|}{ Konsentrasi } \\
\hline & $4 \%$ & $6 \%$ & $8 \%$ & $10 \%$ & $12 \%$ & $14 \%$ & $16 \%$ \\
\hline Kadar Air (\%) & $10,14^{g}$ & $9,63^{f}$ & $9,38^{\mathrm{e}}$ & $9,29^{d}$ & $9,15^{c}$ & $8,80^{b}$ & $8,17^{a}$ \\
\hline Aktivitas Air (\%) & $0,666^{f}$ & $0,621^{\mathrm{e}}$ & $0,592^{d}$ & $0,558^{\mathrm{cd}}$ & $0,550^{\mathrm{bc}}$ & $0,520^{\mathrm{b}}$ & $0,455^{a}$ \\
\hline Daya Rehidrasi (\%) & $68,19^{a}$ & $81,32^{b}$ & $95,37^{c}$ & $103,15^{d}$ & $106,87^{e}$ & $110,87^{f}$ & 113,899 \\
\hline Ekstensibilitas (mm) & $29,63^{a}$ & $30,08^{b}$ & $30,33^{b c}$ & $30,60^{\mathrm{cd}}$ & $30,76^{\mathrm{de}}$ & $31,05^{e}$ & $31,77^{f}$ \\
\hline Elastisitas (mm) & $0,71^{a}$ & $0,82^{b}$ & $0,89^{b c}$ & $0,90^{\mathrm{bc}}$ & $0,94^{c}$ & $1,00^{\mathrm{cd}}$ & $1,06^{d}$ \\
\hline Warna Kering & & & & & & & \\
\hline $\mathrm{L}^{*}$ & 22,13 & 22,60 & 22,98 & 23,05 & 23,28 & 23,62 & 24,11 \\
\hline$a^{*}$ & 1,58 & 1,36 & 1,13 & 0,78 & 0,65 & 0,49 & 0,28 \\
\hline$b^{*}$ & $-0,60$ & $-0,68$ & $-0,84$ & $-0,98$ & $-1,01$ & $-1,04$ & $-1,07$ \\
\hline Chroma & 1,47 & 1,42 & 1,41 & 1,32 & 1,29 & 1,28 & 1,15 \\
\hline Hue & 336,63 & 333,73 & 323,48 & 309,26 & 302,85 & 295,47 & 284,17 \\
\hline
\end{tabular}

Warna Setelah

Direhidrasi dan

DImasak

- $L^{*}$

$-a^{*}$

- $b^{*}$

- Chroma

- Hue

Organoleptik

- Rasa

$34,24 \quad 35,52 \quad 36,48 \quad 37,48 \quad 37,80 \quad 38,33 \quad 38,76$

$\begin{array}{lllllll}3,40 & 3,19 & 3,08 & 2,81 & 2,59 & 2,38 & 2,16\end{array}$

$\begin{array}{lllllll}-0,23 & -0,26 & -0,27 & -0,38 & -0,44 & -0,54 & -0,57\end{array}$

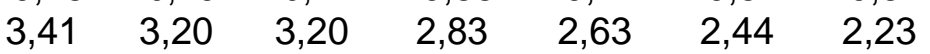

- Kekenyalan

$356,09355,42 \quad 355,07 \quad 352,27 \quad 350,34 \quad 347,17 \quad 345,27$

- Kekenyalan

4,30

4,30

4,30

4,34

4,35

4,33

4,31

- Warna Kering

2,84

2,98

3,19

3,53

4,36

4,53

3,77

Warna

- Setelah

Direhidrasi

dan

$4,45 \quad 4,45 \quad 4,45$

$4,47 \quad 4,49$

$4,49 \quad 4,50$

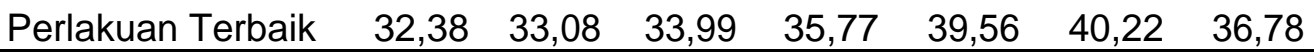

Keterangan: Notasi huruf yang berbeda menunjukkan ada beda nyata pada $\alpha=5 \%$

Pengujian warna kwetiau akan dibedakan menjadi dua yaitu warna kwetiau kering dan warna kwetiau setelah direhidrasi dan dimasak. Skala yang digunakan mulai dari skala 1 (sangat tidak suka), skala 2 (tidak suka), skala 3 (agak tidak suka), skala 4 (netral), skala 5 (agak suka), skala 6 (suka), dan skala 7 (sangat suka). Hasil pengujian organoleptik terhadap rasa menunjukkan nilai 4,30-4,35 yang berarti tidak ada beda 
nyata antara konsentrasi penambahan tapioka terhadap kwetiau kering beras hitam. Hal tersebut terjadi karena perbedaan konsentrasi pati tidak memberikan rasa terhadap kwetiau kering beras hitam sehingga panelis kurang bisa mendeteksi perbedaan rasa kwetiau kering beras hitam.

Hasil pengujian terhadap kekenyalan menunjukkan adanya perbedaan nyata terhadap perbedaan konsentrasi tapioka yang ditambahkan. Kesukaan terhadap kekenyalan kwetiau keirng beras hitam mencapai nilai tertinggi pada konsentrasi $14 \%$ yaitu 4,53 (netral - agak suka) namun mengalami penurunan pada konsentrasi tapioka $16 \%$ yaitu 2,84. Seiring meningkatnya konsentrasi tapioka yang ditambahkan akan mengakibatkan kwetiau kering beras hitam terlalu kenyal dan liat sehingga tidak disukai panelis. Kekenyalan kwetiau kering beras hitam dipengaruhi oleh tapioka yang memiliki kandungan amilosa dan amilopektin yang cukup tinggi sehingga dapat membentuk matriks tiga dimensi yang dapat mengikat air semakin banyak sehingga dihasilkan kwetiau yang kenyal (Anggraini, 2002).

Hasil pengujian kesukaan terhada warna kering berkisar 4,56-4,59, sedangkan hasil pengujian warna setelah direhidrasi dan dimasak berkisar 4,45-4,50 yang berarti tidak ada perbedaan nyata antara konsentrasi penambahan tapioka dalam kwetiau kering beras hitam. Perbedaan konsentrasi tapioka dalam kwetiau beras hitam kering maupun setelah direhidrasi tidak memberikan perbedaan warna yang nyata karena tapioka tidak memberikan warna pada kwetiau kering beras hitam. Namun, perbedaan konsentrasi tapioka akan memberikan peningkatan kecerahan terhadap kwetiau kering beras hitam yang tidak nampak secara visual.

\section{KESIMPULAN}

Perbedaan konsentrasi tapioka berpengaruh nyata terhadap sifat fisikokimia kwetiau kering beras hitam yaitu kadar air, aktivitas air, daya rehidrasi, ekstensibilitas, elastisitas dan organoleptik dari segi kekenyalan. Perbedaan konsentrasi tapioka dalam pembuatan kwetiau kering menurunkan kadar air (8,17\%-10,14\%), dan aktivitas air $(0,455-0,666)$. Namun, meningkatkan daya rehidrasi $(68,19 \%$ $113,89 \%)$, ekstensibilitas $(29,63 \mathrm{~mm}-31,77$ $\mathrm{mm})$, dan elastisitas $(0,71-1,06)$. Rentang nilai lightness $(22,13-24,11)$, chroma $(1,15-$ $1,47)$, dan hue $\left(284,17^{\circ}-336,63^{\circ}\right)$ untuk warna kering. Rentang nilai lightness $(34,24-38,76)$, chroma $(2,23-3,41)$ dan hue $\left(345,27^{\circ}-356,09^{\circ}\right)$ untuk warna kwetiau kering setelah direhidrasi dan dimasak. Perlakuan terbaik kwetiau kering beras hitam adalah konsentrasi tapioka sebanyak $14 \%$.

\section{DAFTAR PUSTAKA}

Anggraini, N. 2002. Pengaruh konsentrasi tepung tapioka, suhu, dan waktu perebusas terhadap mutu kamaboko ikan Bawal Air Tawar (Colossomamacropomum). Skripsi. Fakultas Teknologi Hasil Perikanan.IPB.Bogor.

Caro, G.P., G. Cros, T. Yokota, dan A. Crozier. 2013. Phytochemical Profiles of Black, Red, Brown, and White Rice from the Camargue Region of France, J. Agric. Food Chem., 61 (33): 7976-7986.

Fadiati, A., Mahdiyah, dan Widowati. 2014. Pengaruh Perbedaan Persentase Tepung Komposit terhadap Kualitas Hasil Pemasakan Kwetiau Instan, Seminar Nasional BOSARIS II: Kreasi Inovatif Budaya Nusantara,Universitas Negeri Surabaya.

Fu, B.X. 2008. Asian noodles: History, classification, raw Materials, and processing. Journal of Food Research International 41 (9): 888-902.

Harahap, N. A. 2007. Pembuatan Mie Basah Dengan Penambahan Wortel 
(Daucus carota L.) Skripsi. Fakultas Pertanian. Universitas Sumatera Utara.

Hernawan, E, dan V. Meylani. 2016. Analisis Karakteristik Fisikokimia Beras Putih, Beras Merah, dan Beras Hitam (Oryza sativa L., Oryzanivara dan Oryza sativa L. indica), Jurnal Kesehatan Bakti Tunas Husada, 15 (1): 79-91.

Juniawati. 2003. Optimasi Proses

Pengolahan $\mathrm{Mi}$ Jagung Instan Berdasarkan Kajian Preferensi Konsumen, Skripsi S-1, Departemen Ilmu dan Teknologi Pangan, Fakultas
Teknologi Pertanian, Institut Pertanian Bogor.

Mangiri, J., N. Mayulu, dan S.E.S. Kawengian. 2016. Gambaran Kandungan Zat Gizi pada Beras Hitam (Oryza sativa L.) Kultivar Pare Ambo Sulawesi Selatan, Jurnal E-Biomedik, 4 (1): 1-5.

Ujjawal,K. 2016. Black Rice: Research, History, and Development. Switzerland: Springer International Publishing. 